\title{
Infecciones por amebas de vida libre. Comentarios históricos, taxonomía y nomenclatura, protozoología y cuadros anátomo-clínicos
}

\author{
David Oddó B.
}

Pontificia Universidad

Católica de Chile

Departamento de Anatomía

Patológica

Instituto Nacional del Cáncer

Unidad de Anatomía Patológica

Santiago de Chile.

Recibido: 6 octubre 2006

Aceptado: 24 abril 2006

Correspondencia a: David Oddó Benavides droddopatologo@hotmail.com

\section{Infections caused by free-living amebas. Historical commentaries, taxonomy and nomenclature, protozoology and clinicopathologic features}

Infections caused by free-living amebae constitute one of emergent opportunistic infections with greatest medical interest. Although infrequently, they have been described in almost all world, its diagnosis depends on a high index of suspicion, especially in morpho-pathologic and laboratory studies. Exciting historical features of infections due to free-living amebae, its taxonomy and the present nomenclature are briefly reviewed. An analysis of the protozoology of the most frequent agents is done and, based on the author's own experience and the published one, already established anatomo-clinical entities are described: the primary amebic meningoencephalitis, granulomatous amebic encephalitis, Acanthamoeba keratitis, cutaneous acanthamoebiasis, disseminated infection and other rare isolated locations.

Key words: Free-living amebic infections, primary amebic meningoencephalitis, granulomatous amebic encephalitis, Acanthamoeba keratitis, cutaneous acanthamoebiasis, Balamuthia mandrillaris.

Palabras claves: Infecciones por amebas de vida libre, meningoencefalitis amebiana primaria, encefalitis amebiana granulomatosa, queratitis acantamebiasis, acantamebiasis cutánea, Balamuthia mandrillaris.
S e ha establecido que las amebas de vida libre producen en el hombre enfermedades de curso diverso; desde cuadros agudos y fatales con componentes de predominio necrótico a enfermedades crónicas con reacción inflamatoria granulomatosa. Las características de la enfermedades humanas producidas por estas amebas sólo han sido reconocidas durante los últimos 30 años, ya que el número de humanos infectados por amebas de vida libre es bajo en relación al número de pacientes con Entamoeba histolytica. Debemos considerar a las amebas de vida libre como agentes infecciosos emergentes, tanto patógenos primarios como oportunistas, cuyo diagnóstico resulta muy difícil desde el punto de vista clínico y morfológico.

En la medida que estos agentes son conocidos y sus cuadros clínicos y anátomo-patológicos nos sean familiares, tendremos mayores posibilidades de diagnosticar y eventualmente tratar las infecciones por amebas de vida libre. En este contexto, la agudeza del infectólogo, el parasitólogo y en especial del patólogo ha constituido la base del reconocimiento y diagnóstico de esta nueva enfermedad.
A continuación revisaremos someramente algunos aspectos de la historia, la taxonomía y la nomenclatura, la protozoología, y los cuadros anátomo-clínicos producidos por las amebas de vida libre.

\section{Aspectos históricos de las infecciones por amebas de vida libre}

Las enfermedades asociadas a infección por amebas parasitarias se conocen desde la antigüedad, en especial el cuadro colónico y la enfermedad diseminada cuyo agente causal, Entamoeba histolytica, fue descubierto en 1875 por Fedor Aleksandrovich Losch ${ }^{1}$. Sin embargo, las enfermedades producidas por amebas de vida libre sólo se reconocen, aparentemente, a partir de 1948, cuando se comunicó el caso de un soldado japonés de 22 años, que fuera capturado como prisionero de guerra en enero de 1943, cerca de Buna, Nueva Guinea, y que falleció siete semanas más tarde con una infección amebiana diseminada. E.H. Derrick, que realizó la autopsia, atribuyó la causa de la muerte a un parásito muy parecido o casi idéntico a Iodamoeba 
buetschlii ${ }^{2}$, agente que sido considerado posteriormente por algunos como Naegleria y por otros como una acantamebida ${ }^{3-5}$. El segundo caso de infección humana por amebas de vida libre, del que tenemos información, ocurrió en 1960, en Tucson, Arizona. J.W. Kernoham y col publicaron el caso de una niña de 6 años de edad que falleció con una lesión cerebral descrita como granuloma cerebral, en forma inicial e inexactamente imputado a $I$. buetschlii, pero más tarde se probó que era debido a Acanthamoeba $\mathrm{sp}^{3-6}$. Los dos casos expuestos, de Derrick y de Kernoham, que corresponden de acuerdo a las observaciones y pruebas posteriores realizadas por expertos, a infecciones fatales por amebas de vida libre, se publicaron antes del reconocimiento científico de la capacidad patogénica de estas amebas; en ambos se identificaron las amebas en las lesiones, inicialmente como I. buetschlii, pero fueron posteriormente tipificadas correctamente.

Cabe destacar que un análisis retrospectivo hecho en Gran Bretaña, en 1969, por W.St.C. Symmers encontró dos casos posibles de naegleriosis. Uno afectó a un hombre joven de Essex, Londres, fallecido en 1909, en quien los protozoos fueron observados en una preparación histológica de museo. El segundo caso correspondió a una niña de 10 años de edad, de Belfast, que falleció en 1937, luego de un rápido cuadro fatal de 10 días de evolución, que siguió a un accidente de natación en una piscina?

El primer caso atribuido a Naegleria fue descrito en 1965 por Malcolm Fowler y Rodney F. Carter, en Australia, y correspondió a una meningitis fatal que fue inicialmente imputado a Acanthamoeba sp, pero que luego se catalogó como Naegleria ${ }^{8}$. Posteriormente, en 1966, se describieron en E.U.A. 4 casos de meningoencefalitis en los que se reconocieron elementos parasitarios de tipo amebiano, pero en 3 de ellos no fueron particularmente identificados; en el otro se sugirió que una especie de Acanthamoeba o Hartmannella era responsable de la infección, pero en este caso los protozoos fueron diagnosticados ulteriormente por técnicas inmunohistoquímicas como Naegleria fowleri ${ }^{4,9}$. En base a los casos descritos, a la enfermedad se le denominó como meningoencefalitis amebiana primaria, término que fue acuñado por Cecyl G. Butt ${ }^{10}$.

En 1968, en E.U.A., se estableció que eran amebas del género Naegleria las que producían meningoencefalitis, en base a la identificación de un estado ameboflagelado del protozoo $^{11,12}$.

Varios casos similares de meningoencefalitis fueron comunicados, durante 1968, en otros lugares del mundo, incluido un brote de 16 casos en Praga, Checoslovaquia, que fue diagnosticado en forma retrospectiva por Lubor Cerva y cols; los casos habían ocurrido de 1962 a $1965^{13,14}$. Seis casos más fueron publicados por R. F. Carter ${ }^{15}$. Ocho casos de meningoencefalitis fulminante de la zona de Richmond, Virginia, fueron también comunicados en 1968, 7 de estos casos se habían producido en conjunto, durante los veranos de 1951 y $1952^{12}$. Un estudio retrospectivo de los archivos del Departamento de Patología de Colegio Médico de Virginia, que data de 1920, hecho por el Dr. John G. dos Santos, describió que en todos estos casos el agente causal fue $N$. fowleri, y que el primer caso había ocurrido el 15 de julio de $1937^{16}$.

El primer caso de infección humana por Balamuthia mandrillaris fue comunicado en 1991 en un paciente con síndrome de inmunodeficiencia adquirida (SIDA) ${ }^{17}$.

Pocos casos de infección por $B$. mandrillaris se han descrito en Europa; algunos se han detectado en Australia, Tailandia, Japón y otros países asiáticos. Pero la mayor parte proviene de los estados de América, se han detectado casos en Canadá, E.U.A. y México, en el norte ${ }^{4,18}$. De Sudamérica se han publicado casos provenientes de Argentina, Venezuela, Brasil, y en especial de Perú ${ }^{4,19-22}$. De acuerdo a nuestra información en Chile se han diagnosticado dos casos de encefalitis amebiana granulomatosa por B. mandrillaris, ambos detectados en autopsias, una en 1995 en el Hospital Clínico de la Universidad Católica de Chile y otra en $2003^{22 a}$ en el Hospital Pediátrico Luis Calvo Mackenna de $\mathrm{SSMO}^{22 \mathrm{~b}}$. De África se han descrito aparentemente, sólo casos de infección animal por $B$. mandrillaris, en especial en primates ${ }^{23}$.

Las primeras descripciones de las amebas del género Naegleria se remontan, aparentemente, a 1909 cuando Kart Naegler describió una ameba no patógena, la Naegleria gruberi; más tarde, en 1912 considerada como Digastigomoeba por Alexeieff ${ }^{24}$. Esta ameba es morfológicamente similar a la especie oportunista, que en 1970 fue denominada Naegleria fowleri, basado en el aislado desde un paciente en Australia y en animales de experimentación ${ }^{25}$. Hasta la fecha, se han publicado cerca de 200 casos de infección por $N$. fowleri ${ }^{5}$.

El protozoo Acanthamoeba sp fue descrito por primera vez en 1930, por Sir Aldo Castellani como un microorganismo saprófito que se desarrollaba en cultivos de levaduras de Cryptococcus paraoseus; M. Douglas denominó a la ameba como Hartmannella castellani en el género Hartmannella, pero posteriormente fue reclasificado como Acanthamoeba castellani ${ }^{26,27}$. La contaminación espontánea de cultivos de células de riñón de mono por amebas de vida libre fue publicada en $1957^{27,28}$. En 1958 Clyde Culbertson y col demostraron el potencial patogénico de ambas en animales, induciendo una encefalitis en ratones tras la inoculación de una Acanthamoeba que contaminaba las células en cultivo durante la producción de la vacuna de contra la 
poliomielitis al interior de Laboratorios Eli Lilly. Las amebas fueron denominadas como Acanthamoeba sp cepa Lilly A-1, pero más tarde y en honor al Dr. Clyde G. Culbertson se le denominó como Acanthamoeba culbertsoni $^{29,30}$. Actualmente, se ha establecido que $A$. castellani, A. culbertsoni, Acanthamoeba polyphaga y probablemente otras especies, son capaces de producir infecciones en seres humanos y animales ${ }^{31}$. La literatura registra aproximadamente 150 casos de encefalitis amebiana granulomatosa y cerca de 1.000 queratitis debidas a Acanthamoeba $\mathrm{sp}^{3-5}$.

El primer aislado de B. mandrillaris se efectuó en 1990, en un mandril (babuino mandril, Papio sphinx) ${ }^{32}$, y hasta la fecha se ha identificado como agente causal en cerca de 100 casos publicados de infección en humanos $^{4}$. La descripción de los primeros casos de compromiso cutáneo relacionado con amebas del Orden Leptomyxa es atribuida a Visverara y cols ${ }^{5,31}$.

En el año 2001 se publicó el primer y único caso de encefalitis amebiana causada por Sappinia diploidea, en un paciente de 38 años de edad, cuya biopsia reveló una inflamación necrosante y hemorrágica con trofozoitos de doble núcleo, cuyo caracteres morfológicos estructurales y ultraestructurales correspondieron a $S$. diploidea. El paciente fue tratado con varios fárma$\cos$ antiamebianos y sobrevivió ${ }^{33,34}$.

\section{Taxonomía y nomenclatura de las amebas de vida libre}

De acuerdo a la nomenclatura actual, las amebas son seres vivos del reino Protozoa. Las amebas de vida libre que afectan al ser humano pertenecen a dos phyla del reino Protozoa: Percolozoa y Rhizopoda ${ }^{3-5,35}$.

Phylum Percolozoa: Agrupa organismos primitivos, algunos de los cuales pueden ser ameboflagelados con un flagelo transitorio, no tienen aparato de Golgi, pero poseen mitocondrias o hidrogenosomas y peroxisomas. El phylum incluye la clase Heterolobosea, el orden Schyzopyrenida, la familia Vahlkampfiidae; y los géneros Naegleria y Vahlkampfia.

Phylum Rhizopoda: Agrupa organismos con pseudopodos como medio de locomoción y alimentación, mitocondrias con crestas tubulares. La mayoría de las especies son de vida libre. El phylum incluye 2 clases, a saber:

- Clase Lobosea:

Orden Hartmannellida:

- Familia Hartmannellidae Género: Hartmannella.
- Familia Acanthamoebidae y Género: Acanthamoeba.

Orden Leptomyxa:

- Familia Leptomyxidae Género: Balamuthia.

- Clase Entamoebidae:

Orden Amoebida:

- Familia Entamoebidae

Géneros: Entamoeba, Endolimax (?), Iodamoeba (?).

Existen numerosas amebas de vida libre en el suelo y en el agua de la naturaleza, pero solamente especies de los géneros Naegleria, Vahlkampfia, Acanthamoeba, Balamuthia y Hartmannella han sido encontrados en pacientes humanos. Naegleria y Vahlkampfia pertenecen al phylum Percolozoa; Acanthamoeba, Balamuthia y Hartmannella pertenecen al phylum Rhizopoda. Las especies del género Naegleria son amebas muy primitivas, tienen generalmente, de uno a cuatro flagelos temporales en algunas etapas de su ciclo de vida, por lo que reciben el nombre de ameboflagelados. El género Vahlkampfia no tiene flagelos temporales.

Las especies de importancia en medicina humana hasta ahora, son $N$. fowlerii (se han empleado como sinónimos: Naegleria aerobia y Naegleria invadens), Vahlkampfia sp, Hartmannella rhysodes, Hartmannella vermiformis, Hartmannella sp, A. castellanii, A. culbertsoni, Acanthamoeba astronyxis, $A$. polyphaga, Acanthamoeba healyi, Acanthamoeba sp, B. mandrillaris, y $S$. diploidea.

Naegleria australiensis y otras especies de Naegleria producen infección en animales de experimentación, tales como el ratón, pero no han sido encontradas en seres humanos. Hay en la naturaleza además, un grupo grande de amebas de vida libre de los géneros Naegleria y Acanthamoeba que no son, aparentemente, patógenas para el hombre, entre las cuales debe mencionarse a Naegleria gruberi cuya morfología es similar a N. fowleri.

Aunque las especies del género Hartmannella son muy comunes en la naturaleza, sólo en muy pocas ocasiones se han recuperado de infecciones humanas, una vez del cerebro e identificada como $H$. rhysodes y otras, de lesiones corneales y LCR e identificada como $H$. vermiformis, o simplemente como una Hartmannella sp. La mayoría de los casos publicados de infección humana por Hartmannella han sido correctamente reclasificados como Acanthamoeba o Balamuthia ${ }^{3,4}$.

Sappinia diploidea pertenece a la familia Thecamoebidea, orden Euamoebida, subclase Gymnamoebia y clase Lobosea. 
Para denominar a las amebas de vida libre se ha usado también la denominación de amebas anfizoicas, término descriptivo que evoca la capacidad de estos microorganismos para vivir en el ambiente externo, es decir exozoico, y para vivir como parásito facultativo en el cuerpo de animales y seres humanos, es decir endozoico. Por otra parte, el empleo del nombre de Limax amebae para referirse a las amebas de vida libre se debe a la apariencia viscosa de las colonias que desarrollan in vitro algunos grupos de estos protozoos, las que remedan colonias micóticas.

El término acantamebida es empleado por algunos autores para referirse en términos generales a cualquier especie de los géneros Acanthamoeba, Balamuthia y Hartmannella ${ }^{3}$.

\section{Protozoología de las amebas de vida libre}

\section{Género Naegleria}

El ciclo de vida de $N$. fowleri incluye una forma vegetativa o trofozoito, un estado flagelado y un estado quístico. Los trofozoitos corresponden a protozoos ameboídeos que en preparaciones frescas miden 15 a $25 \mu$ de diámetro mayor, tienen un abundante citoplasma vacuolado o granular, y un gran núcleo central, claro y redondo con un nucleolo esférico prominente y refringente; su movimiento, se realiza a través de seudópodos redondeados, o lobopodios, de tamaño variable (Figura 1A). En los tejidos infectados, como el SNC, los trofozoitos son redondeados y miden 8 a $12 \mu$ de diámetro. La forma flagelada que se observa en el medio ambiente o en medios acuosos en el laboratorio, es usualmente piriforme, mide 12 a $18 \mu$ de diámetro mayor, y es biflagelada (Figura 1B), pero puede tener
10 o más flagelos; esta forma puede reconvertirse a trofozoito. Los quistes son formaciones esféricas, de 8 a $12 \mu$ de diámetro mayor, aunque pueden alcanzar hasta $20 \mu$, tienen un contorno liso y una densa pared refráctil con uno o dos poros aplanados (Figura 1C). Los quistes de $N$. fowleri no se observan en los tejidos infectados, sólo se aprecian en el medio ambiente.

Los trofozoitos de $N$. fowleri son termofílicos y pueden desarrollarse y multiplicase por división binaria a temperaturas de 40 a $45^{\circ} \mathrm{C}$ en el medio ambiente y en cultivos celulares de laboratorio. En el medio acuoso y cálido los trofozoitos pueden originar la forma flagelada, la que puede reconvertirse a trofozoito. Como respuesta a condiciones ambientales adversas los trofozoitos se enquistan, el enquistamiento se produce en el agua y en los medios de cultivo, pero no en los tejidos. Los quistes son altamente susceptibles a la desecación y se destruyen rápidamente en condiciones de sequedad. En un ambiente propicio -fresco, acuoso y de alta temperatura- ocurre el desenquistamiento $^{3,4}$.

Naegleria fowleri es un protozoo ubicuo y presente en todo el mundo, ha sido encontrado, bajo condiciones normales y temperatura ambiente, en el suelo, polvo del aire ambiental, agua dulce de piscinas y lagos, reservorios de agua doméstica, sistemas de humidificación, aguas residuales y en la nariz de individuos sanos. También se desarrolla bien en climas tropicales y temperaturas calurosas entre 40 y $45{ }^{\circ} \mathrm{C}$, en aguas termales naturales limpias y contaminadas, aguas cloradas de piscinas temperadas. Las cepas de $N$. fowleri adaptadas a altas temperaturas, sobre $46{ }^{\circ} \mathrm{C}$, son termofílicas y virulentas en los animales de experimentación, mientras que las cepas no termofílicas son avirulentas ${ }^{3,4,36}$.

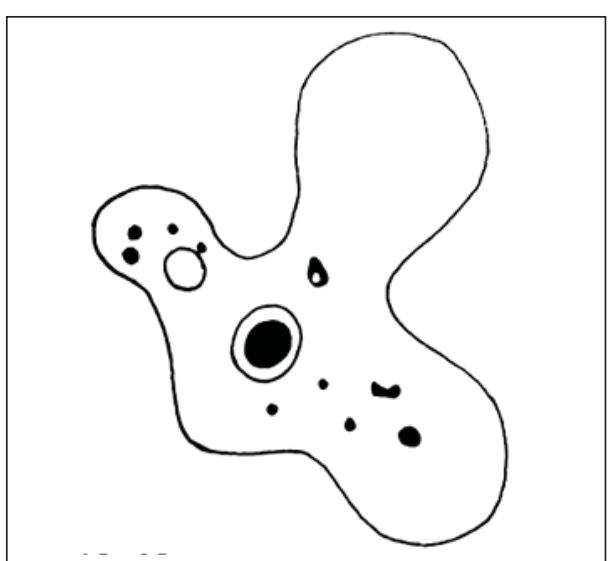

Figura 1A. Esquema de un trofozoito de Naegleria fowleri; mide 15 a $25 \mu$ y presenta lobopodios.

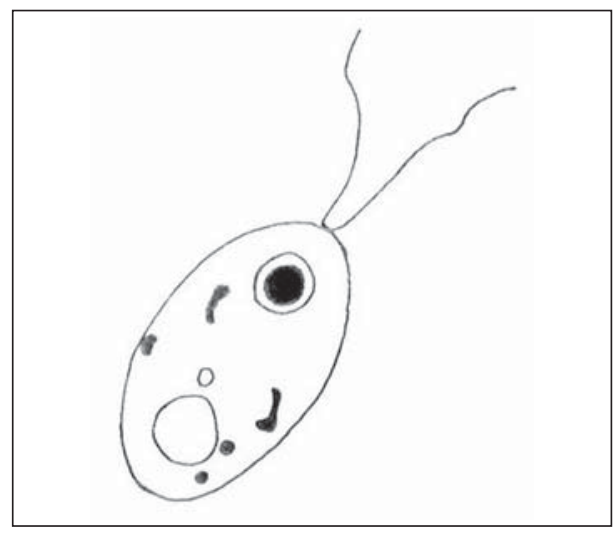

Figura 1B. Esquema de una forma ameboflagelada de Naegleria fowlerii; mide 12 a $18 \mu$ y tiene habitualmente dos flagelos.

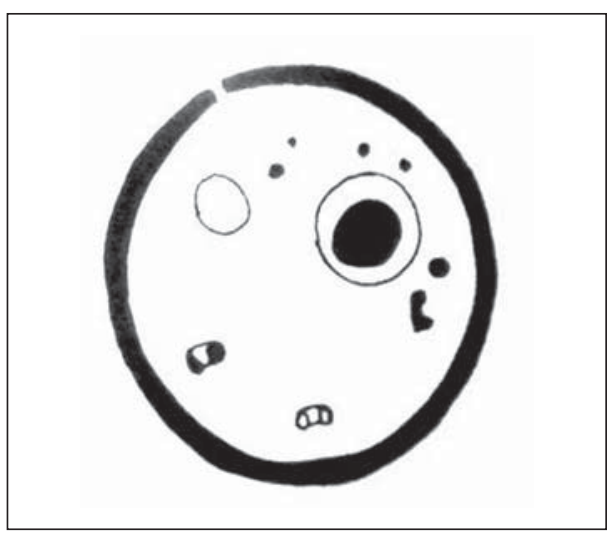

Figura 1C. Esquema de un quiste de Naegleria fowlerii; mide 8 a $12 \mu$ y presenta uno o dos poros aplanados. 


\section{Género Acanthamoeba}

El ciclo de vida de las diferentes especies de acantamebas presenta una forma vegetativa o trofozoito y una forma quística o quiste. En preparaciones frescas, lo trofozoitos ameboides de las diferentes especies de Acanthamoeba son irregulares y presentan múltiples

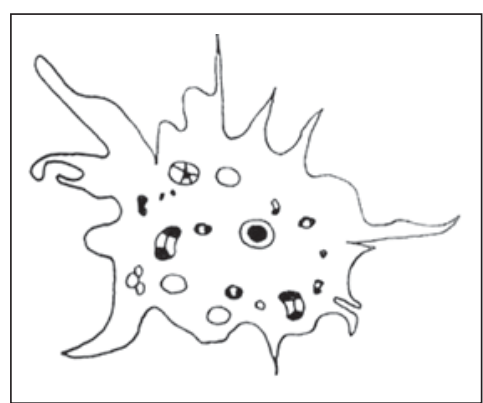

Figura 2A. Esquema de un trofozoito de Acanthamoeba sp; mide 20 a $40 \mu$ y presenta acantopodios.

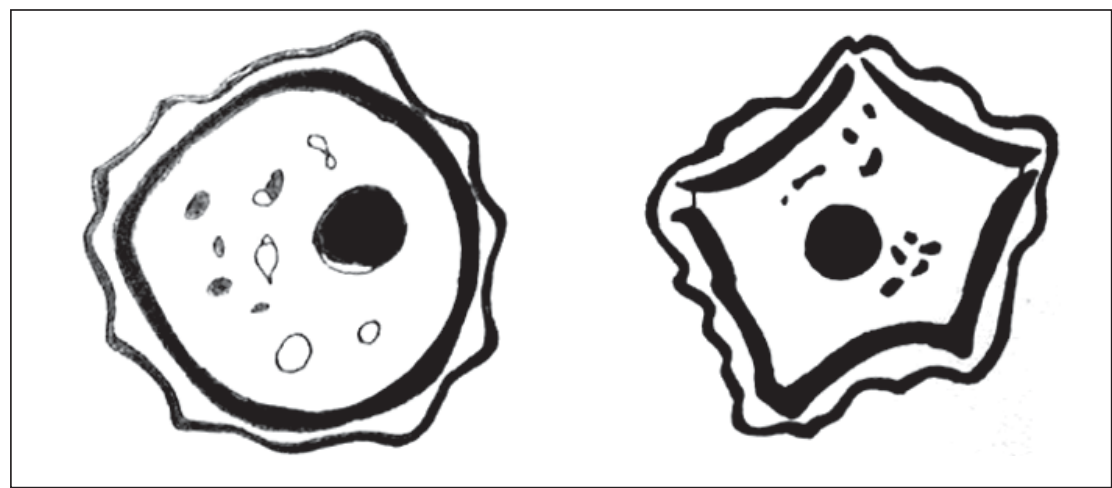

Figura 2B. Esquema de un quiste de Acanthamoeba sp; mide 15 a $25 \mu$, es esférico o poligonal y tiene una doble pared gruesa.

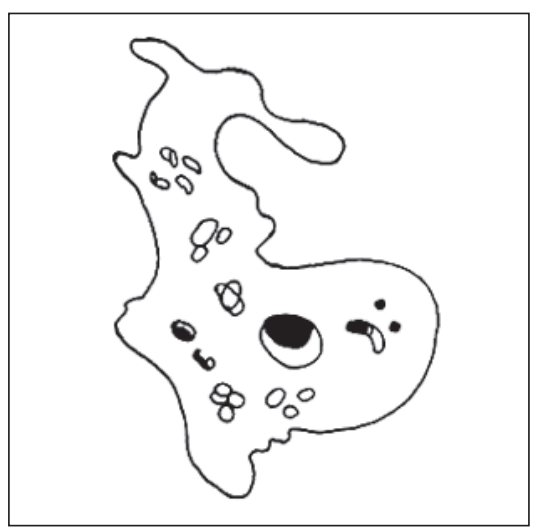

Figura 3A. Esquema de un trofozoito de Balamuthia mandrillaris; mide 15 a $60 \mu$ y presenta lamelipodios.

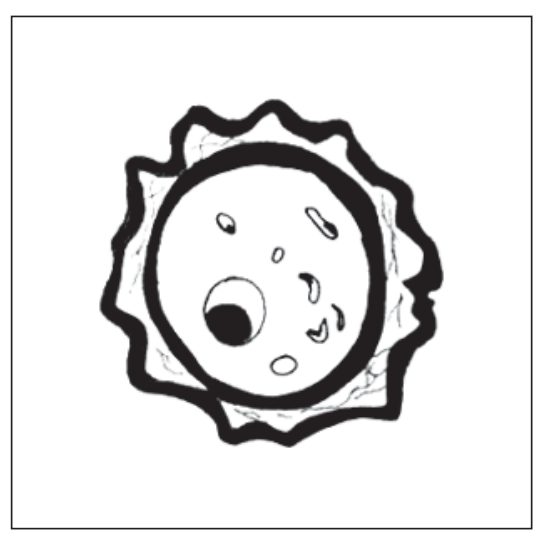

Figura 3B. Esquema de un quiste de Balamuthia mandrillaris; mide 15 a $30 \mu$ y tiene una triple pared gruesa. proyecciones pseudopodiales retráctiles, filamentosas o espinosas llamadas acantopodios (Figura 2A). El tamaño de los trofozoitos varía de acuerdo a cada especie, con promedios de 20 a $40 \mu$; así los diámetro mayores son: 21 a $45 \mu$ para A. castellanii, 25 a $60 \mu$ para A. astronyxes, y 14 a $41 \mu$ para A. polyphaga. El citoplasma es abundante y tiene un aspecto granular y vacuolar; además tienen un núcleo claro, central y esférico con un prominente y denso nucleolo redondeado. En los tejidos infectados, los trofozoitos de Acanthamoeba sp miden de 15 a $35 \mu$ de diámetro mayor, son ovoideos y de contornos ligeramente irregulares, de pared delgada, citoplasma granular y vacuolado, con un único núcleo esférico, anfófilo y un prominente nucleolo central intensamente hematoxifílico a manera de un cariosoma; la superficie interna de la membrana nuclear no muestra cromatina periférica, un signo que ayuda a diferenciar estos trofozoitos de los de E. histolytica. En los cortes de tejido teñidos con hematoxilina y eosina, los acantopodios no se tiñen, el nucleolo se tiñe violeta obscuro, y el citoplasma se colorea en forma eosinofílica, la membrana nuclear es delicada y frecuentemente su delimitación es definida solamente por vacuolas perinucleares.

Los quistes de Acanthamoeba sp, que son esféricos o poligonales y tienen una doble pared, miden de 6 a $30 \mu \mathrm{m}$ de diámetro, aunque generalmente son de 15 a $25 \mu \mathrm{m}$ (Figura 2B). El citoplasma es granular, con numerosas vacuolas alimentarias, distribuidas alrededor del núcleo: una, y algunas veces dos de estas vacuolas alimentarias, son contráctiles y vacían su contenido acuoso a intervalos de 40 a 50 segundos. El núcleo es evidente como una débil estructura refráctil, con un aún más refráctil cariosoma redondeado.

Las acantamebas son ubicuas y se encuentran ampliamente distribuidas en la naturaleza, se han aislado de enfriadores de agua, filtros de acondicionadores de aire, agua de mar, agua de charcos, aguas residuales, lagunas, ríos, polvo, estaciones de lavado ocular, incluso de la boca y de la nariz de individuos sanos.

\section{Balamuthia mandrillaris}

El ciclo de vida de B. mandrillaris es probablemente semejante al de Acanthamoeba sp, al igual que el aspecto y el tamaño de los trofozoitos y quistes. Sin embargo, los trofozoitos, que miden de 15 a $60 \mu$, tienen un peculiar retículo endoplasmático acintado, y se desplazan lentamente mediante amplias proyecciones aplanadas, llamadas lamelipodios (Figura 3A), a diferencias de las prolongaciones espinosas del género Acanthamoeba. Los quistes miden de 15 a $30 \mu$ de diámetro y tienen una triple pared característica (Figura 3B). 
Balamuthia mandrillaris no había sido aislada del medio ambiente, como Naegleria y Acanthamoeba, solamente se había recuperado de muestras de autopsia de humanos y animales infectados ${ }^{3-5,37}$; empero recientemente se ha publicado el aislamiento de esta ameba de vida libre del ambiente en un entorno asociado a un caso de encefalitis ${ }^{38}$.

\section{Sappinia ovoidea}

Sappinia ovoidea ha sido aislada de las heces de vaca y otros herbívoros. Resulta interesante esta ameba de vida libre, ya que al revés de casi todas las amebas, que no tienen reproducción sexual, S. ovoidea parece tener actividades sexuales o parasexuales ${ }^{39,40}$.

\section{Cuadros anátomo-clínicos producidos por amebas de vida libre}

Los cuadros anátomo-clínicos asociados a infección por amebas de vida libre son la meningoencefalitis amebiana primaria, la encefalitis amebiana granulomatosa, la queratitis acantamebiana, la dermatitis acantamebiana o acantamebiasis cutánea y la dermatitis asociada a $B$. mandrillaris, un cuadro diseminado con compromiso del SNC, piel, pulmón, riñón, próstata útero, y otras localizaciones aisladas inhabituales.

\section{Meningoencefalitis amebiana primaria}

Definición y etiología: la meningoencefalitis amebiana primaria (MAP) es producida por N. fowleri y corresponde a un cuadro agudo y fulminante que afecta a personas saludables que 3 a 7 días antes han realizado deportes acuáticos en piscinas, estanques o ríos, en los meses de verano, o en piscinas temperadas. Los protozoos penetran a través del neuroepitelio olfatorio originando una meningoencefalitis necrosante y purulenta, con compromiso predominante de la base del cerebro, tronco cerebral y cerebelo; en los cortes histológicos se encuentran sólo trofozoitos, especialmente perivasculares; en el ser humano no se observan quistes en los tejidos ${ }^{3,4,41,42}$.

Epidemiología: La MAP ocurre en todo el mundo, con un mayor número de casos encontrados en E.U.A., Australia, y algunos países europeos que tienen un mayor interés en este cuadro. La mayoría de las infecciones humanas en E.U.A., han ocurrido en la mitad sudeste del país; todos durante los meses de verano. El número de casos comunicado en la literatura permanece bajo, estimado en 200 en todo el mundo hasta 1990; pero ahora el número es probablemente cercano a $\operatorname{los} 250$, aunque algunos de ellos aún no han sido publicados ${ }^{3,4}$.

Naegleria fowleri ha sido aislada de la mucosa nasal de individuos sanos en numerosas ocasiones; sin embargo, el cómo ocurren estas infecciones humanas es materia de especulación. La mayor parte de las infecciones humanas son adquiridas después de las zambullidas en agua fresca, especialmente en corrientes de aguas termales contaminadas, aguas termales naturales, aguas de piscinas temperadas, o aguas estancadas que son calentadas sobre lo normal durante los meses de verano. Por esta razón se ha asumido que los trofozoitos del agua son los responsables de las infecciones humanas, pero esto no ha sido firmemente establecido. $N$. aerobia, una especie patógena para el ratón, es transmitida más eficientemente durante su estado flagelado ${ }^{3-5}$.

Varias especies de Naegleria han sido aisladas de las vías nasales y del tracto respiratorio superior de individuos sanos; algunos de estos aislados han sido identificados solamente como Naegleria o Naegleria gruberi, una especie no patógena, pero una pocas han sido catalogadas como patógenas. El significado de estos descubrimientos en la epidemiología de estas infecciones permanece poco claro, además el pasaje de la infección de persona a persona no ha sido documentado y parece que la reactivación de una infección endógena no está descrita ${ }^{3-5,42}$.

Patogenia: El mecanismo por medio del cual las amebas invaden el cerebro y producen la enfermedad no se conoce. Más aún, toda la información acerca de la patogénesis de esta amebiasis se ha deducido de la experimentación animal e in vitro, y la veracidad de la aplicación de este conocimiento a la infección humana natural resulta discutible.

Ha sido bien establecido que las cepas virulentas de $N$. fowlerii tienen un efecto citopatogénico in vitro sobre células de mamífero en cultivo, fenómeno no observado con especies no patógenas o que sólo se ha observado en un grado menor. Se ha demostrado que existe desmielinización de la sustancia blanca en las infecciones por Naegleria, especialmente en las zonas adyacentes a la sustancia gris inflamada; este fenómeno no se debe a alteraciones vasculares o circulatorias con trombosis como ocurre en otras encefalitis. La desmielinización observada en la infecciones por Naegleria es producida por un efecto fosfolipolítico que actúa directamente sobre la mielina. Una vía de demostración experimental de este efecto es la prueba en tubos con solución de esfingomielina incubada con los parásitos; una proteasa de $30 \mathrm{kDa}$ aislada desde cultivos destruye fácilmente tejido de mamíferos. La enzima de $N$. gruberi no patogénica no es termotolerante y no opera sobre $30^{\circ} \mathrm{C}$. Otras investigaciones han mostrado que la destrucción celular no se debe solamente a lisis por acción enzimática, sino que también a fagocitosis por la propia ameba; en realidad, 
se ha visto que estos dos mecanismos operan bajo circunstancias diferentes. Cepas de $N$. fowleri en cultivo ingieren pedazos de células usando su amebostoma y cepas pasadas seriadamente en animales, que se consideran más virulentas, producen lisis celular. Se ha propuesto que, ya sea, un agente infeccioso transportado por la ameba o una proteina de $50 \mathrm{kDa}$ aislada del protozoo pueden actuar como factores infecciosos responsables de la lisis celular ${ }^{3-5}$.

Dado que la infección por Naegleria produce rápidamente la muerte, la respuesta inmune al parásito ha sido poco estudiada ${ }^{3-5}$.

Cuadro clínico: La MAP ocurre principalmente en individuos sanos, inmunocompetentes, niños o adultos jóvenes, que relatan, en la mayoría de los casos, el antecedente de baño o zambullida en agua fresca justo antes del inicio del cuadro. El periodo de incubación dura 3 a 7 días, aunque en algunos casos es mayor a dos semanas. Los síntomas comienzan abruptamente, con fiebre leve y malestar general, algunas veces acompañados de rinitis y odinofagia; estos síntomas progresan rápidamente, con acentuada cefalea y fiebre, seguido por vómitos, rigidez de nuca y signos de irritación meníngea. Hacia el final del tercer día de evolución, el paciente está muy desorientado, si no comatoso. Algunos síntomas leves de compromiso respiratorio superior pueden estar presentes. Al ingreso al hospital, el diagnóstico es generalmente de meningitis piógena; en el hospital, el cuadro clínico es de un continuo deterioro, somnolencia, y algunas veces con convulsiones. La punción lumbar arroja un fluido turbio con presión elevada. Otros síntomas y signos neurológicos están ausentes. El paciente fallece de insuficiencia respiratoria en menos de 10 días de iniciados los síntomas. Unos pocos pacientes han sido aparentemente tratados en forma exitosa, pero la identificación del parásito en algunos de estos casos ha sido cuestionada ${ }^{3-5}$.

Las pruebas de laboratorio muestran un aumento de los leucocitos polimorfonucleares en sangre. El LCR tiene elevados contenidos de proteínas, células mononucleares, trofozoitos amebianos móviles y hematíes. Por las características del LCR y el cuadro clínico, la enfermedad frecuentemente se confunde con meningitis viral. Tomografías computarizadas muestran un proceso meníngeo con obliteración de los espacios alrededor del cerebro medio o sólo edema difuso inespecífico.

Cuadro anátomo-patológico: En la necropsia, el cerebro está hinchado, congestivo y con leve a intenso edema. Las meninges están difusamente hiperémicas, con un escaso exudado purulento, especialmente en la base del cerebro. Los bulbos olfatorios están friables y necróticos, con evidencia de herniación del uncus del hipocampo. La corteza cerebral tiene una superficie petequial y zonas con hemorragias mayores asociadas a pequeñas zonas de destrucción y necrosis. Estos cambios, variables en su distribución, son encontrados con mayor frecuencia en la base de los lóbulos frontales y lóbulos temporales, como también en el hipotálamo, cerebro medio y puente cerebral. En secciones coronales, el cerebro acusa cambios relacionados al aumento de la presión intracraneana, como herniaciones; el resto aparece en general de aspecto conservado.

Los cambios microscópicos en la MAP consisten en pequeños focos de destrucción y necrosis, hemorragia, infiltrado celular mononuclear y polimorfonuclear, y típicos trofozoitos amebianos. El examen de la cavidad nasal muestra cambios inflamatorios en el epitelio neuro-olfatorio, los cuales se extienden hacia el cerebro a través de la lámina cribosa del etmoides, junto a un marcado edema; una rinitis edematosa con exudado leucocitario polimorfonuclear ha sido vista en algunos pacientes p $^{3-5,41,42}$.

En la cavidad craneal, las meninges están hiperémicas con moderada a intensa infiltración por linfocitos. Los leucocitos polimorfonucleares son escasos y las amebas son observadas en el fondo como discretas estructuras redondeadas usualmente poco tingibles con un núcleo prominente. Las lesiones de la sustancia gris, que algunas veces se extienden a la sustancia blanca, consisten en focos microscópicos de destrucción y necrosis con células inflamatorias y trofozoitos amebianos. Frecuentemente los parásitos son encontrados alrededor de los vasos sanguíneos, aún penetrando en el tejido cerebral y siguiendo los espacios de Virchow-Robin. Necrosis de pequeños vasos sanguíneos con destrucción de paredes vasculares, formación de trombos y hemorragias petequiales son signos habituales en la MAP. Las amebas circulan por el LCR hacia los ventrículos y otras áreas. En ninguna instancia, ya sea en el LCR o en tejido cerebroespinal, se han identificados quistes de $N$. fowleri. La respuesta inflamatoria exudativa y productiva es mínima o está ausente, probablemente debido a la rapidez con que $N$. fowleri se multiplica en los tejidos y a la evolución "galopante" de la enfermedad.

Una lesión, algunas veces asociada a la MAP, fuera del SNC, es una miocarditis focal consistente en pequeñas áreas de destrucción y necrosis con infiltrado celular inflamatorio, aunque no se han encontrado parásitos, por lo que se cree que esta lesión se debe a un estado de hipoperfusión.

Diagnóstico: El diagnóstico clínico de MAP es complicado de establecer, principalmente porque el pequeño número de casos comunicados hace difícil que los médicos clínicos estén familiarizados con la infec- 
ción. Si el diagnóstico es sospechado clínicamente, las amebas deben ser investigadas en muestras frescas de LCR y en muestras fijadas y teñidas.

La identificación de las amebas en preparados frescos de LCR es difícil, se requiere del conocimiento de sus características morfológicas. Para establecer el diagnóstico deben encontrarse amebas móviles de 7 a $15 \mu$ de diámetro, con un gran nucleolo y un citoplasma vacuolado. Bajando el condensador del microscopio, para aumentar el contraste o empleando el microscopio de contraste de fases, se facilita la visualización de este parásito. Si el LCR es centrifugado y el sedimento resuspendido en agua, las amebas son transformadas a un estado flagelado, característica que debe ser tenida en mente y explorada en el laboratorio en todos los casos en que se sospeche un caso de infección por Naegleria. El sedimento del LCR debe ser teñido con Giemsa, hematoxilina y eosina, o una tinción tricrómica. Un preparado de cytospine de LCR tomado postmorten y teñido con Papanicolaou dio buenos resultados en un caso comunicado ${ }^{3}$. Los parásitos teñidos son reconocidos con mayor facilidad que los no teñidos. Además, hoy se dispone de una técnica directa con anticuerpos inmunofluorescentes que puede ser de utilidad.

Es en los tejidos de material de autopsia, donde el diagnóstico de Naegleria es hecho con mayor frecuencia; los trofozoitos son idénticos a los observados en los frotis de LCR, excepto que en los tejidos las amebas son más pequeñas, con un diámetro de 7 a $8 \mu$ y tienen un núcleo que mide cerca de 2 a $3 \mu$ de diámetro; en algunos trofozoitos no se observa núcleo dado el plano de corte de sección examinado. Hay que recordar que ésta es una ameba muy pequeña. Los trofozoitos son encontrados, ya sea, aislados o en grupos dentro del tejido cerebral, en el intersticio de las meninges, piamadre y aracnoides, en la superficie cerebral y surcos, y en los espacios de Virchow-Robin siguiendo los vasos sanguíneos de tamaño medio y pequeño. La membrana del trofozoito está pobremente delineada, y el citoplasma es vacuolado y pálido con la tinción de hematoxilina-eosina. La estructura más prominente es el núcleo con una membrana nuclear no aparente y un nucleolo grande y teñido obscuro (Figuras 4A y 4B). Naegleria puede ser cultivada en medios libres de células de manera similar a Acanthamoeba sp.

La diferenciación de Naegleria de otras amebas limax y E. histolytica en los tejidos es ayudada por el tamaño de los trofozoitos. El diámetro promedio de los trofozoitos de Naegleria en tejido fijados y procesados es de 7,5 $\mu$. Naegleria no ha sido descrita fuera del epitelio neuro-olfatorio y el cerebro, no forma quistes en los tejidos y no produce focos macroscópicos de destrucción y necrosis en el encéfalo.
Tratamiento: Sólo los pacientes con MAP que tienen un diagnóstico etiológico en fases muy iniciales de la enfermedad tienen alguna posibilidad de sobrevivir. Los muy pocos pacientes que han sobrevivido fueron todos tratados con anfotericina $B$, en dosis de $1,0 \mathrm{mg} / \mathrm{kg} /$ día Fármacos de elección para el tratamiento son anfotericina $\mathrm{B}$, miconazol y rifampici$\mathrm{na}^{5,43}$.

\section{Encefalitis amebiana granulomatosa}

Definición y etiología: Varias especies del género Acanthamoeba y B. mandrillaris representan a agentes oportunistas que causan el cuadro denominado encefalitis amebiana granulomatosa (EAG); ésta afecta, naturalmente, a pacientes debilitados, desnutridos, diversos tipos de inmunocomprometidos, incluidos pacientes con SIDA, y niños pequeños aunque el antecedente de inmunocompromiso es relevante en las infecciones por Acanthamoeba sp, no así en los casos producidos por B. mandrillaris. La enfermedad corresponde a una encefalitis necrosante y hemorrágica aguda, subaguda o crónica, multifocal con angeitis necrótica, algunas células macrofágicas y células gigantes multinucleadas, con presencia de trofozoitos y quistes parasitarios característicos. A pesar del nombre de encefalitis granulomatosa, el componente granulomatoso suele ser irrelevante o estar ausente. La puerta de entrada es el tracto respiratorio o la piel, desde donde y siguiendo la vía hematógena, o una progresión local siguiendo vías nerviosas, las amebas llegan al $\mathrm{SNC}^{3,6-8,44}$. Sólo dos casos de encefalitis atribuidos al género Vahlkampfia han sido diagnosticados en base a su apariencia morfológica en los tejidos; muy pocos casos han sido imputados genuinamente a especies del género Hartmanella; y un caso ha sido atribuido a $S$. diploidea $a^{3,4,5,33,41}$.

Epidemiología: Las amebas de vida libre están en todo el mundo, y han sido encontrados casos de infección humana en cada lugar donde médicos y observadores con conocimiento han comenzado a averiguar de su existencia. Infecciones humanas con estas amebas han ocurrido, posiblemente, desde el amanecer de la humanidad. Su reconocimiento durante las últimas décadas es el resultado del enorme avance en el tratamiento de las enfermedades infecciosas en la era antimicrobiana. El SIDA ha remarcado la importancia de las acantamebidas por su capacidad de inmunodeprimir y predisponer a infecciones oportunistas con alta morbilidad y mortalidad.

Dado que los quistes de acantamebidas son encontrados en el aire, las infecciones humanas pueden adquirirse a través de la vía aérea superior y por contacto de mucosas expuestas como es la conjuntiva. Acanthamoeba y Hartmannella han sido aisladas en 
cultivos de tórulas tomadas de la nariz y del tracto respiratorio superior de individuos sanos, pero son especies de Hartmannella las que se aíslan con mayor frecuencia en estas condiciones. La transmisión de humano a humano no ha sido demostrada. Así, todas las infecciones son adquiridas desde el ambiente y el término econosis ha sido propuesto para referirse a las enfermedades causadas por organismos que son de vida libre pero que ocasionalmente se comportan como parásitos facultativos.

Patogenia: La patogenicidad de las especies de Acanthamoeba, Balamuthia y Hartmannella es incuestionable. Que algunas de estas especies son altamente virulentas es también algo evidente dada la secuencia temporal del desarrollo de los síntomas y el grado de la enfermedad visto en algunas infecciones humanas. Sin embargo, estas amebas necesitan de huéspedes que estén inmunocomprometidos o que tengan una deficiencia inmune que facilite su transformación en parásito facultativo. Infecciones por Balamuthia que han sido encontradas en adultos jóvenes y niños sin un déficit inmune conocido siguieren que este género puede ser más virulento que Acanthamoeba y Hartmannella. El mecanismo por el cual el parásito invade los tejidos y produce lesiones es desconocido. Trabajos al respecto sólo se han hecho acerca de la interacción de la ameba con los tejidos y células sobre la córnea.

Cuadro clínico: El compromiso del cerebro por acantamebidas ocurre en todas las edades, igual en ambos sexos, sin predilección racial para Acanthamoeba sp, pero con aparente predilección de hispanoamericanos en caso de B. mandrillaris en California ${ }^{3-}$ $5,44,45$. Las manifestaciones clínicas son variables pero en la mayoría de los pacientes se presenta como una encefalopatía focal o difusa y con signos de irritación meníngea. Algunas veces las manifestaciones clínicas dependen de una lesión que ocupa espacio, con los consiguientes signos de aumento de la presión intracraneana. Los síntomas más comunes son anormalidades del estado mental, letargo, cefalea, hemiparesias y meningismo. La fiebre está presente en cerca de la mitad de los casos y, en un menor grado, náuseas, vómitos, anorexia, ataxia, y afasia. El curso de la enfermedad es subagudo o crónico, de 7 a 120 días. Algunos pacientes tienen, simultáneamente, lesiones cutáneas ulceradas.

Las anormalidades de laboratorio más significativas en el LCR son pleocitosis con 20 a $100 \%$ de linfocitos, una glucosa normal o límite, aumento del nivel de proteínas, y unas pocas células polimorfonucleares. La glucorraquia normal o límite y el recuento subanormal de células polinucleares ayuda a diferenciar esta infección de la meningoencefalitis bacteriana. Técnicas imagenológicas, tales como TAC, angiograma cerebral y técnicas con galio, usualmente demuestran graves lesiones vasculares localizadas en cualquier parte dentro del cerebro, de manera especial en el cerebelo o cerebro medio. En algunos pacientes, la TAC revela grandes oclusiones arteriales y la RM demuestra lesiones en la médula espinal. Una disminución del espacio ventricular puede ser demostrado. En una niña de 7 años de edad, la presentación fue como la de una masa tumoral en el área parietal izquierda, con incoordinación de la extremidad superior y debilidad izquierda, incremento de los reflejos tendinosos profundos, y signos de Babinski positivo en el lado derecho. Una infección con Balamuthia sp se presentó como un aparente glioma del tronco cerebral. La gran mayoría de los pacientes se deteriora progresivamente hasta llegar al coma y la muerte.

Cuadro anátomo-patológico: El examen macroscópico del cerebro en la EAG muestra tumefacción con edema de los hemisferios cerebrales con evidencias de un incremento de la presión intracraneana: herniación del uncus del hipocampo y de las amígdalas cerebelosas o desviación lateral de uno de los hemisferios. La superficie de la corteza cerebral tiene zonas con exudado inflamatorio sobre las meninges. En las secciones de corte, las regiones comprometidas aparecen como zonas de reblandecimiento de aspecto destruido, necrótico y hemorrágico extendiéndose dentro de la sustancia gris y blanca; estas zonas son más comunes en el cerebelo, tronco cerebral, y ganglios de la base. Las lesiones corticales están llenas con restos de un material pardo obscuro y friable y se extiende por varios centímetros desde la corteza a la materia blanca; algunas de estas lesiones son indistinguibles de infartos hemorrágicos.

Los cambios tisulares microscópicos consisten en una destrucción y necrosis extensa con hemorragia e infiltrado celular mononuclear y polinuclear en cantidades variables, pero las amebas son lo más remarcable de la lesión. En los tejidos viables el hallazgo característico es una inflamación granulomatosa. Los granulomas recientes pueden tener amebas en su centro; mientras que los granulomas viejos, compuestos por algunos histiocitos y células gigantes, engloban a trofozoitos y quistes parasitarios. Sin embargo, los granulomas pueden estar ausentes. Los quistes se encuentran en diferentes estados de desintegración y son finalmente destruidos por las células macrofágicas. Los parásitos suelen estar poco resaltados en el tejido necrótico; no así en el tejido cerebral viable, donde son más nítidos y numerosos, usualmente siguiendo los espacios de Virchow-Robin y alrededor y dentro de las paredes vasculares de los vasos sanguíneos de tamaño mediano y grande. Ambos, trofozoitos y quis- 
tes, son reconocidos fácilmente en casi todos los casos (Figuras 5A y 5B). Algunos de los vasos sanguíneos muestran inflamación y necrosis de las paredes con trombosis, un mecanismo que puede ser responsable en parte de la gran cantidad de tejido necrótico y destruido, y por ende de la apariencia de infarto de estas lesiones. Algunos vasos sanguíneos pequeños tienen necrosis fibrinoide. El infiltrado celular es variable: algunos pacientes con la médula ósea hematopoyética intacta tienen abundantes linfocitos y células polimorfonucleares; otros, con escasos o sin elementos linfoides y mieloides, no tienen prácticamente

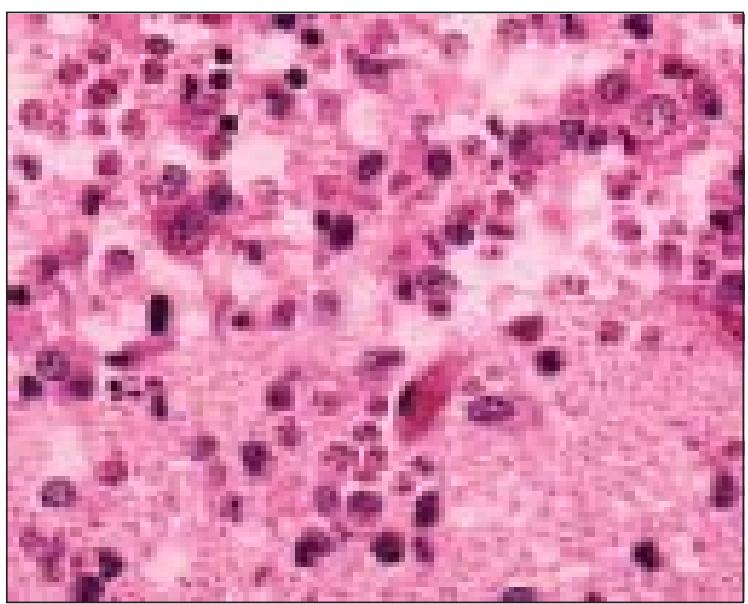

Figura 4A. Meningoencefalitis amebiana primaria. Inflamación meníngea mononuclear con necrosis y destrucción de la sustancia gris adyacente y múltiples trofozoitos de Naegleria fowleri (H \& E X 200, aumento original).

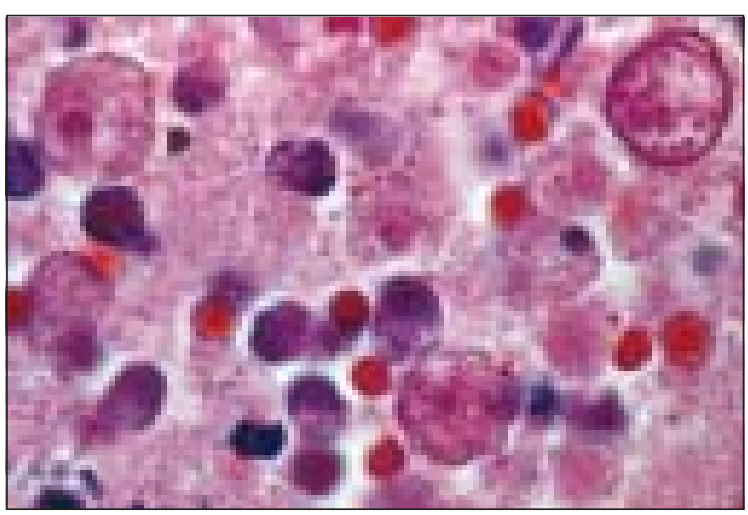

Figura 5A. Encefalitis amebiana granulomatosa. Tejido cerebral necrótico y destruido con varios trofozoitos y quistes de Balamuthia mandrillaris ( $\mathrm{H} \& \mathrm{EX} 1250$, aumento original). reacción inflamatoria. La presencia de macrófagos es variable. Algunas veces los macrófagos contienen amebas fagocitadas, especialmente quistes en estados variables de degradación. Los quistes en las células gigantes multinucleadas tienen un ectoquiste liso dado la capacidad digestiva de los macrófagos. Pueden estar presentes células plasmáticas, especialmente si la lesión ha evolucionado por algún tiempo.

Diagnóstico: El diagnóstico de EAG es sospechado clínicamente en base de la historia del paciente y los síntomas, pero la demostración e identificación de la ameba en los tejidos o fluidos corporales es requerida

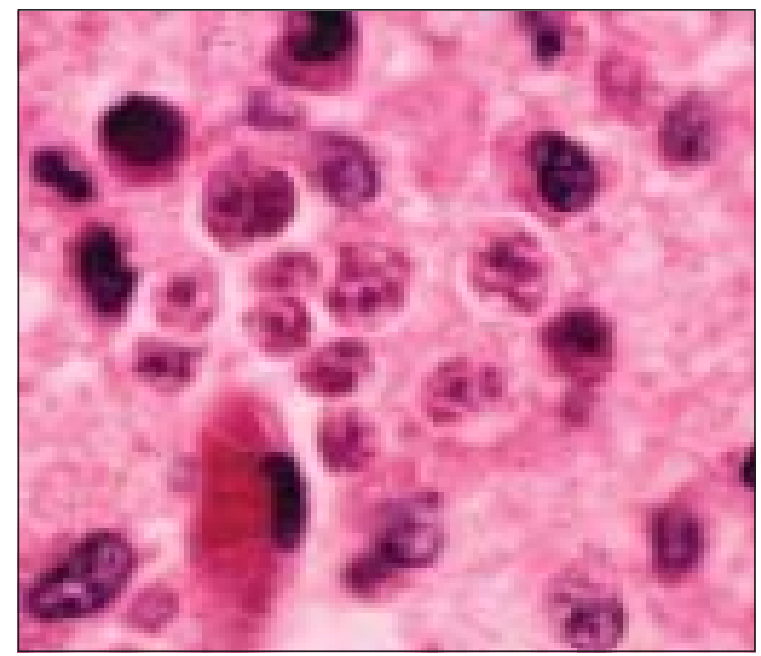

Figura 4B. Meningoencefalitis amebiana primaria. Varios trofozoitos de Naegleria fowleri de disposición perivascular (H \& E X 1250, aumento original).

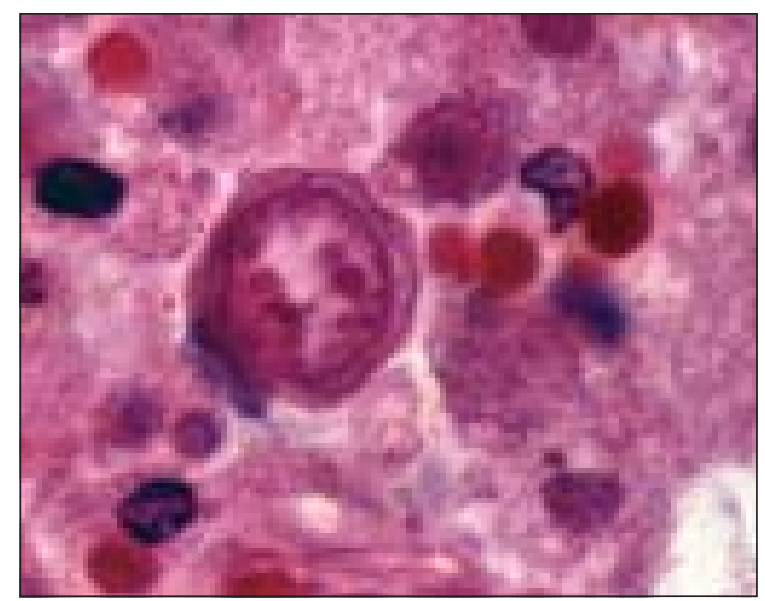

Figura 5B. Encefalitis amebiana granulomatosa. Tejido cerebral necrótico y destruido con un quiste de Balamuthia mandrillaris con la característica pared trilaminar (H \& E X 1250, aumento original). 
para su confirmación. El aislamiento del parásito en cultivos es necesario para la identificación bioquímica e inmunológica de la especie. Las muestras deben ser recolectadas en medio salino estéril de Page para transportarlas al laboratorio. Acanthamoeba y Hartmannella pueden ser cultivadas en medio libres de células compuestos por agar no nutritivo. Las placas son preparadas, enfriadas y sembrados con Escherichia coli suspendida en $0,5 \mathrm{ml}$ de solución salina estéril hasta hacer una solución coloreada ligeramente lechosa. Entonces las placas son refrigeradas y están listas para usarse en cualquier momento. Las muestras de LCR o fragmentos de tejidos de biopsia son colocados sobre las placas e incubados a temperatura ambiente.También ha sido recomendado el filtrado de la muestra a través de un cedazo de celulosa estéril y la siembra del filtrado sobre el agar. Los trofozoitos se multiplican y alimentan sobre las bacterias, las cuales no se multiplican porque el agar no es nutritivo. Las placas son examinadas con microscopio de bajo aumento, buscando pequeños espacios circulares desprovistos de bacterias con trofozoitos activos en los márgenes. Los cultivos deben ser examinados diariamente, a partir del día 2 después de la siembra y continúa por 8 a 10 días, tiempo al cabo del cual las placas pueden ser eliminados. Balamuthia requiere cultivos celulares para su aislamiento; en caso de duda, las muestras clínicas deben ser cultivadas tanto en placas de agar como en cultivos de tejido celular. Si el parásito se desarrolla en agar, es Acanthamoeba o Hartmannella; si se desarrolla, solamente, en células de cultivo celular es Balamuthia. De los cultivos se deben hacer preparaciones en fluido salino para observación de la ameba al fresco o frotis para su identificación en tinciones. Se recomienda el empleo de hematoxilina y eosina, Giemsa, Papanicolaou, y tinciones tricrómicas para la demostración de trofozoitos y quistes. Hay que enfatizar que las amebas en los frotis de fluidos corporales son más grandes que las vistas en los cortes de tejido, debido a la retracción que ocurre durante el procesamiento de los tejidos. El calcoflúor, un quimiofluorescente que tiene gran afinidad por los polisacáridos de la pared del quiste amebiano, ha sido usado para el diagnóstico rápido de quistes.

Acanthamoeba puede ser identificada en preparaciones húmedas de LCR en base al tamaño de la ameba, característicos acantopodios, un núcleo con un gran nucleolo y citoplasma vacuolado. Hartmannella y Balamuthia tienen algunas de estas características pero no tienen acantopodios. El tamaño, la presencia de quistes, los acantopodios, y la ausencia de organismos flagelados, son signos de que diferencian las acantamebidas de Naegleria. Son útiles también tinciones con anticuerpos fluorescentes indirectos.
En los tejidos, trofozoitos y quistes de Acanthamoeba, Hartmannella y Balamuthia están presentes en un número variable, probablemente dependiente de la duración de la infección. Los trofozoitos en los tejidos miden, en promedio, $22 \mu$ de diámetro, y tienen el característico núcleo con un gran nucleolo que se tiñe obscuro con hematoxilina y eosina; el citoplasma es vacuolado, y los acantopodios que son fácilmente vistos en los frotis, no son reconocibles en los cortes de tejido, a menos que se tiñan con hematoxilina férrica. Los quistes son también fácilmente identificados por su gruesa pared, ectoplasma irregular con ostiolos conteniendo la ameba; frecuentemente están retraídos y representados por masas obscuras con un núcleo similar al del trofozoito. La pared no se tiñe con hematoxilina y eosina, aparece refringente, y con una gran variabilidad de tamaño en relación a la pared de los trofozoitos.

La distinción entre Acanthamoeba, Hartmannella, Vahllkampfia y Balamuthia bajo microscopia de luz no es posible. En microfotografías electrónicas, $B$. mandrillaris generalmente carece de acantopodios, el quiste es más redondeado, y la pared es gruesa con tres capas. La distinción entre este género y E. histolytica en secciones de tejidos está basada en su morfología nuclear y es relativamente fácil; más aún, la presencia de quistes en los tejidos elimina totalmente la posibilidad de Entamoeba. Los modelos histológicos de las lesiones producidas por Naegleria, es decir una meningoencefalitis, y la producida por acantamebidas, es decir granulomas y extensa necrosis, ayudan a distinguir las dos infecciones en la mayoría de los casos.

También hoy se dispone de técnicas de inmunofluorescencia e inmunohistoquímicas para tejidos congelados e incluidos en parafina para la identificación de acantamebidas ${ }^{45}$. Recientemente se ha publicado el desarrollo de ensayos de RPC que permitiría identificar a B. mandrillaris y Acanthamoeba sp en tejido fijados en formalina para estudios retrospectivos y en casos de biopsias de pacientes vivos posiblemente infectados ${ }^{46,47}$.

Tratamiento: La EAG no tiene un tratamiento efectivo. Sólo se han comunicado algunos casos anecdóticos de pacientes recuperados; dos casos con tratamiento combinado de ketoconazol, rifampicina y cotrimoxazol $^{49}$ y un caso con pentamidina, clorhexidina y ketoconazol tópicos ${ }^{50}$. Experiencias in vitro sugieren que el uso de diamino derivados tales como pentamidina y propamidina junto a miconazol -ketoconazol y 5fluocitosina pueden ser efectivos en el tratamiento de este cuadro ${ }^{51}$. En cuanto al tratamiento causal de la EAG por B. mandrillaris, sólo hace poco se han comunicado dos casos de pacientes con encefalitis por esta ameba que han sobrevivido a la infección; en ellos se 
hizo un diagnóstico serológico precoz y se trataron con una asociación de medicamentos, incluyendo fluocitocina, pentamidina, fluconazol, sulfadiazina, macrólidos (azitromicina y claritromicina) y fenotiacinas (tioridacina y trifluoperacina) $^{52}$.

\section{Queratitis y queratoconjuntivis acanthamebiana}

Definición y etiología: La queratitis y queratoconjuntivitis acanthamebiana (QA) corresponde a un proceso inflamatorio crónico activo producido por Acanthamoeba sp, que afecta la córnea y a veces la conjuntiva y otras estructuras oculares, asociado al antecedente de un traumatismo corneal y la exposición a agua contaminada. Los factores de riesgo para el desarrollo de la enfermedad son el uso de lentes de contacto y su lavado con soluciones salinas caseras. Esta infección afecta tanto a pacientes inmunocompetentes como inmunocomprometidos. El agente causal aislado con mayor frecuencia es $A$. polyphaga, debido probablemente al hecho que ésta sobrevive, con mayor frecuencia, cuando es expuesta a algunos de los agentes recomendados para la desinfección de los lentes de contacto $^{3-5}$. En otros pacientes se ha cultivado $A$. castellanii, y Acanthamoeba griffini ha sido caracterizada sobre bases moleculares. Recientemente, una especie de Hartmannella fue aislada de la córnea en una coinfección con Vahlkampfia ${ }^{3,5}$. Aparentemente no se ha aislado $B$. mandrillaris de muestras oculares pero no es improbable que este género sea responsable de algunas infecciones, especialmente en algunos casos en los cuales las amebas no son cultivadas en los medios necesarios.

Epidemiología: La QA ha comenzado a constituir una infección importante, especialmente en individuos que usan lentes de contacto, particularmente blandos. Hasta 1996 se habían publicado más de 750 casos en todo el mundo; pero esta cifra no representa el verdadero número de casos porque solamente incluye los pacientes comunicados en la literatura o derivados al CDC, Atlanta, E.U.A. ${ }^{3-5,51}$.

Patogenia: Los trabajos experimentales acerca de la interacción de la ameba sobre la córnea han demostrado que Acanthamoeba sp produce en la córnea una queratitis necrosante progresiva; se visto que esta queratitis ocurre solamente en humanos, cerdos y hámsters, pero otros animales son refractarios a la infección. En la córnea de los animales susceptibles los parásitos se apegan firmemente al epitelio corneal, produciendo profundas grietas y exfoliación del epitelio. En estudios in vivo, los parásitos atacan sólo el epitelio corneal previamente dañado, nunca el epitelio intacto, y la presencia de células de Langerhans en la córnea previene el desarrollo de las lesiones. Los macrófagos aparecen como primera línea de defensa para atacar por ingestión a los parásitos. El cómo los parásitos se adhieren a la córnea intacta o dañada, y el cómo se producen las lesiones es desconocido. El rol de la colagenasa, aislada del sobrenadante de un cultivo de $A$. castellani, parece jugar un rol en la producción de la lesión, dado su actividad in vitro e in vivo contra el tejido corneal. Raramente, la QA se extiende más allá de la córnea y produce una uveítis. En los pacientes con SIDA y encefalitis acanthamebiana se ha descrito una uveítis sin compromiso corneal, como también una uveítis anterior aislada y una retinitis ${ }^{3-5,51}$.

Cuadro clínico: Los síntomas y signos de presentación de la QA, usualmente corresponde a los derivados de una úlcera o abrasión corneal que frecuentemente remeda la queratitis adenoviral. Las personas que no usan lentes de contacto, frecuentemente tienen una historia de la presencia de un cuerpo extraño en el ojo, trauma ocular, o lavado de sus ojos con agua sucia. Los usuarios de lentes de contacto, especialmente blandos, se quejan de un discomfort repentino e irritación. Los síntomas comienzan con dolor creciente, epífora y fotobofia. El examen ocular usualmente revela enrojecimiento y frecuentemente defectos del epitelio corneal, los cuales pueden pasar a ser persistentes o recurrentes. Otros pacientes presentan una queratitis superficial puntata, erosiones y opacidades subepiteliales, o infiltrados, irregularidades, líneas o solevantamientos epiteliales corneales. Si no se sospecha el diagnóstico, el tratamiento convencional conlleva a un mayor deterioro en un periodo de semanas a varios meses, con etapas de quiescencia y recrudescencia, especialmente si se ha instaurado una terapia corticoesteroidal. La queratitis progresa implacablemente y pueden desarrollarse una conjuntivitis e iritis; sigue un marcado deterioro de la agudeza visual con destrucción de la córnea, necesitando una terapia intensa y de una queratoplastia. Un anillo de infiltrado estromal se desarrolla en más de dos tercios de los individuos afectados, el que se manifiesta como un infiltrado o absceso corneal anular paracentral; si esta condición es reconocida por los médicos clínicos, puede dar origen a un diagnóstico temprano ${ }^{3-5,51}$.

Cuadro anátomo-patológico: El examen de las muestras de biopsia de córnea o de la córnea entera si se ha practicado un transplante, revela una leve a intensa reacción inflamatoria granulomatosa compuesta por células mononucleares y polimorfonucleares, asociada a zonas de destrucción y necrosis inicialmente y luego a una reacción reparativa proliferativa. Ambos, trofozoitos y quistes de Acanthamoeba sp, son reconocidos en una cantidad variada (Figuras 6A y 6B).

Diagnóstico: Puede hacerse por varios medios: biop- 
Figura 6A. Queratitis acanthamebiana. Tejido corneal necrótico y destruido con un quiste esférico de Acanthamoeba sp (H \& E X 1250, aumento original).

Figura 6B. Queratitis acanthamebiana. Tejido corneal necrótico y destruido con un quiste poligonal de Acanthamoeba sp ( $H$ \& E X 1250, aumento original).
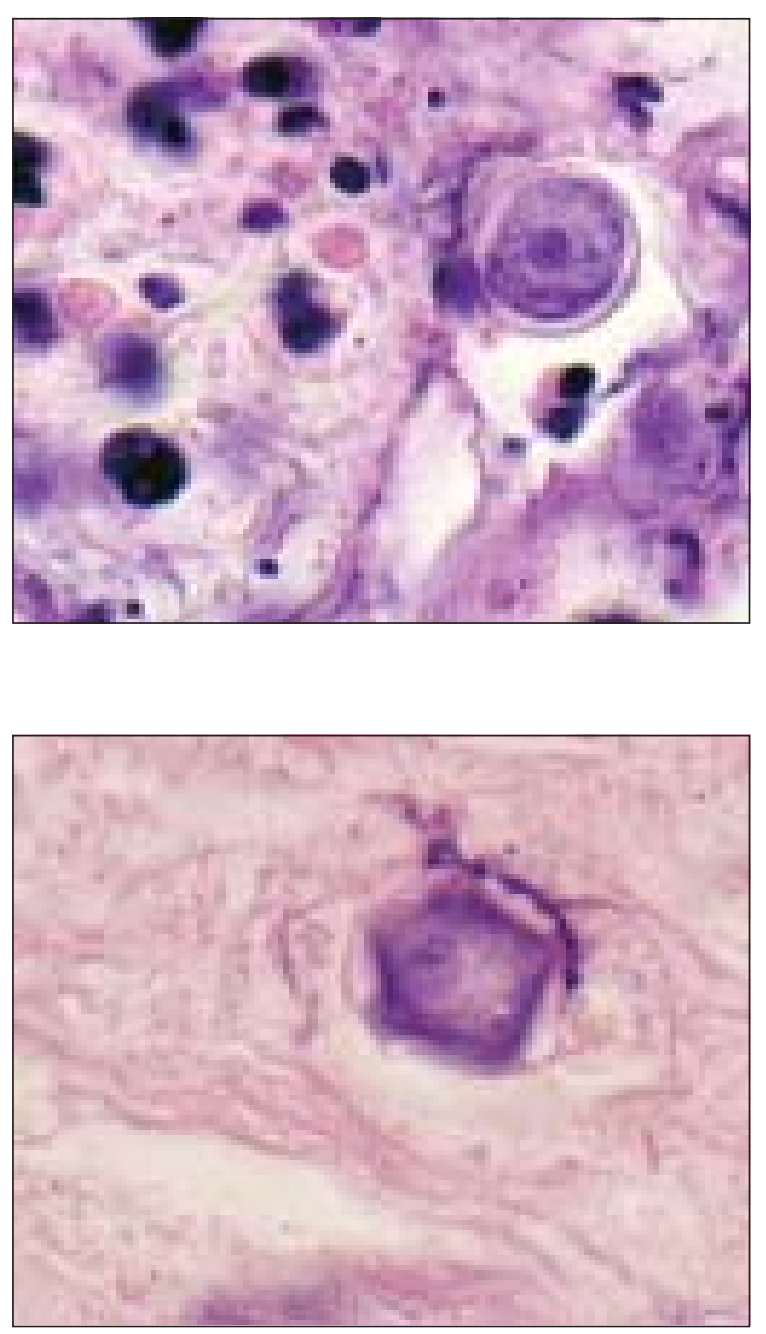

sia con uso de técnicas especiales, incluido el calcoflúor blanco; cultivos, RPC, hibridación in situ fluorescente, citometria de flujo, y microscopia confocal ${ }^{51,53-56}$.

Tratamiento: Algunos pacientes con QA han sido tratados con éxito, aunque aún carecemos de un tratamiento óptimo. Se han usado con buenos resultados medicamentos oftálmicos como el isotianato de propamidina (Brolene ${ }^{\circledR}$ ) y la dibromo propamidina. Se ha comunicado el uso efectivo de polimixina $\mathrm{B}$, nitrato de miconazol, neomicina, neosporina, ketoconazol y clotrimazol, asociados al isotianato de propamidina. Algunos ensayos han mostrado un gran potencial curativo de la biguanida polihexametileno. Casos con extensa destrucción requieren de una queratoplastia con injerto o trasplante de córnea ${ }^{51}$.

\section{Dermatitis acanthamebiana}

La dermatitis acanthamebiana o acanthamebiasis cutánea (DA) es una inusual infección oportunista de la piel producida por amebas de vida libre del género Acanthamoeba; puede ser una lesión primaria de la piel o manifestación secundaria de una infección diseminada.

Aunque la infección ha sido descrita en pacientes aparentemente inmunocompetentes, afecta básicamente a inmunocomprometidos, ya sea desnutridos, pacientes con cáncer, individuos con enfermedades consuntivas que reciben terapia inmunodepresora, y en especial gente con SIDA. Algunos casos son claramente primarios, pero en otros no se puede descartar una diseminación hematógena en un cuadro de EAG típico, con puerta de entrada en el tracto respiratorio inferior. En algunos casos las manifestaciones de la lesiones cutáneas anteceden a las de la invasión del $\mathrm{SNC}$, incluso con la epidermis intacta en varios enfermos y la presencia de trofozoitos y quistes en las zonas dérmicas inflamadas. Otros pacientes muestran lesiones ulceradas con abundante exudado purulento. En pacientes con SIDA, la persistencia de lesiones cutáneas luego de tratamientos antibacterianos y antimicóticos ineficaces, debe hacer sospechar en la presencia de acantamebas, las cuales deben ser buscadas en forma dirigida y cuidadosa por el patólogo en las muestras de biopsia de piel correspondientes $^{3-5}$.

Las lesiones corresponden a procesos inflamatorios que afectan la epidermis, dermis e hipodermis, habitualmente granulomatosos, a veces con granulomas maduros bien constituidos, y en otras oportunidades con formaciones granulomatoides, con células gigantes de tipo cuerpo extraño aisladas; generalmente está presente un componente alterativo necrosante de magnitud variada, en especial en las lesiones ulceradas y extensas, y en particular en pacientes con SIDA. Los parásitos pueden ser escasos en número y difíciles de encontrar, o abundantes con numerosos quistes asociados a granulomas. El aspecto morfológico de las amebas es semejante al descrito en lesiones tisulares del SNC, pero pueden confundirse con otros agentes infecciosos o con macrófagos ${ }^{51}$.

La mortalidad reportada de la DA sin compromiso del SNC es de aproximadamente $73 \%$; cuando además esta afectado el encéfalo, la mortalidad llega a $100 \%{ }^{57}$.

En los cuadros de dermatitis por B. mandrillaris no se observan quistes y el número de trofozoitos en la piel afectada es escaso, requiere que el patólogo sospeche el diagnóstico, pues frecuentemente los trofozoitos son confundidos con células macrofágicas o histiocitos ${ }^{58}$.

En los casos de compromiso cutáneo por amebas de vida libre, debe recalcarse la importancia de la identificación temprana de la naturaleza de la lesión de la piel, pues muchas veces ésta precede por hasta varios 
meses la aparición de las manifestaciones del compromiso neurológico; una sospecha clínica temprana, seguida de un diagnóstico de certeza y tratamiento precoces podrían modificar el ominoso pronóstico de la enfermedad ${ }^{58}$.

En la forma diseminada de infección por acantamebidas, se ha observado compromiso del SNC, piel, pulmón, riñón, próstata y útero, con un cuadro histológico semejante al descrito previamente. Otras localizaciones aisladas inusuales han correspondido a hueso, senos paranasales y oído.

\section{Resumen}

Las infecciones por amebas de libre constituyen una de las infecciones oportunistas emergentes del mayor interés médico; aunque su frecuencia es baja, se han descrito en casi todo el mundo y su diagnóstico depende del grado de sospecha clínica, pero especialmente de su pesquisa anatomopatológica y de laboratorio. A continuación se exponen, someramente, los apasionantes aspectos históricos de las infecciones por amebas de vida libre; se revisa la taxonomía y las nomenclatura actual de estas amebas; se analiza las protozología de los agentes más frecuentes; y se describen, con algún detalle y basado en la experiencia propia y en la publicada, los ya bien establecidos cuadros anatomoclínicos producidos: la meningoencefalitis amebiana primaria, la encefalitis amebiana granulomatosa, la queratitis acantamebiana, la dermatitis acantamebiana o acantamebiasis cutánea, la infección diseminada y otras localizaciones aisladas raras.

\section{Referencias}

1.- Losch F A. Massenhafte Entwickelung von Amoben in dickdarn. Virchow Arch Pathol Anat Klin Med 1875; 65: 196-211.

2.- Derrick E H. A fatal case of generalized amoebiasis due to a protozoon closely resembling, Eif not identical with Iodamoeba buetschlii. Trans R Soc Trop Med Hyg 1948; 42: 191-8.

3.- Gutiérrez Y. Free-Living Amebae. En: Y. Gutiérrez (Ed). Diagnostic Pathology of Parasitic Infections with Clinical Correlations. Ed. Oxford University Press. New York 2000; p 114-42.

4.- Martínez A J, Visvesvara G S. Free-living, amphizoic and opportunistic amebas. Brain Pathol 1997; 7: 583-98.

5.- Martínez J M, Visvesvara G S, Chandler F W. Free-Living Amebic Infections. En D H Connors, F W Chandler, D A Schwartz, H J Manz, E E Lack (Eds). Pathology of infectious Diseases, Vol II. Ed. Appleton \& Lange. Stamford, Connecticut. 1997; p 1163-76.

6.- Kernoham J W, Magath T B, Schloss G T. Granuloma of brain probably due to Endolimax williamsi (Iodamoeba buetschlii). Arch Pathol 1960; 70: 576-80.

7.- Symmers WStC. Primary amoebic meningoencephalitis in Britain. Br Med J 1969; 4: 449-54.

8.- Fowler M, Carter R F. Acute pyogenic meningitis probably due to Acanthamoeba sp: A preliminary report. Br Med J 1965; 2: 740-3.

9.- Patras D, Andujar J J. Meningoencephalitis due to Hartmannella (Acanthamoeba). Am J Clin Pathol 1966; 46: 226-33.

10.- Butt C G. Primary amebic meningoencephalitis. N Engl J Med 1966; 274: 1473-6.
11.- Butt C G, Baro C, Knorr R W. Naegleria (sp) identified in amebic encephalitis. Am J Clin Pathol 1968; 50: 568-74.

12.- Callicott J H J. Amebic meningoencephalitis due to free-living amebas of the Hartmannella (Acanthamoeba) - Neagleria group. Am J Clin Pathol 1968; 49: 84-91.

13.- Cerva L, Novak K. Amoebic meningoencephalitis: sixteen fatalities. Science 1968; 160: 92.

14.- Cerva L, Novak K, Culbertson C G. An outbreak of acute, fatal amebic meningoencephalitis. Am J Epidemiol 1968; 88: 436-44.

15.- Carter R F. Primary amoebic meningoencephalitis: clinical, pathological, and epidemiological features of six fatal cases. J Pathol Bacteriol 1968; 96: 1-25.

16.- dos Santos J G. Fatal primary amebic meningoencephalitis: a retrospective study in Richmond, Virginia. Am J Clin Pathol 1970; 54: 737-42.

17.- Anzil AP, Rao C, Wrzolek M A, Visvesvara G S, Sher J H, Kozlowski P B. Amebic meningoencephalitis in a patient with AIDS caused by a newly recognized opportunistic pathogen. Leptomyxid Ameba. Arch Pathol Lab Med 1991; 115: 21-5.

18.- Riestra-Castañeda J M, Riestra-Castañeda R, González-Garrido A A, Peña Moreno P, Martínez A J, Visvesvara G S, et al. Granulomatous amebic encephalitis due to Balamuthia mandrillaris (Leptomyxiidae): report of four cases from Mexico. Am J Trop Med Hyg 1997; 56: 603-7.

19.- Taratuto A L, Monges J, Acefe J C, Meli F, Paredes A, Martínez A J. Leptomyxid amoeba encephalitis: report of the first case in Argentina. Trans R Soc Trop Med Hyg 1991; 85: 77.
20.- Martínez A J, Guerra A E, García-Tamayo J, Céspedes G, González-Alfonzo J E, Visvesvara G S. Granulomatous amebic encephalitis: a review and report of a spontaneous case from Venezuela. Acta Neuropathol 1994; 87: 430-4.

21.- Chimelli L, Hahn M D, Scaravilli F, Wallace S, Visvesvara G S. Granulomatous amoebic encephalitis due to leptomyxid amoebae: report of the first Brazilian case. Trans R Soc Trop Med Hyg 1992; 86: 635.

22.- Recavarren-Arce S, Velarde C, Gotuzzo E, Cabrera J. Amoeba angeitic lesions of the central nervous system in Balamuthia mandrillaris amoebiasis. Hum Pathol 1999; 30: 269-73.

22a.- Oddó D, Ciani S, Vial P. Encefalitis amebiana granulomatosa por Balamuthia mandrillaris. Primer caso diagnosticado en Chile. Rev Chil Infect 2006; 23 (3): 229-33 (en este número).

22b.- Cuevas M, Smoje G, Jofré L, Ledermann W, Noemí I, Berwart F, et al. Meningoencefalitis granulomatosa por Balamuthia mandrillaris: Reporte de un caso y revisión de la literatura. Rev Chil Infect 2006; 23 (3): 234-9 (en este número).

23.- Rideout B A, Gardiner C H, Stalis I H, Zuba J R, Hadfield T, Visvesvara G S. Fatal infections with Balamuthia mandrillaris (a free-lining amoeba) in gorillas and other Old World primates. Vet Pathol 1997; 34: 1522.

24.- Naegler K. Entwicklungseschichtliche studien uber amoben. Arch Protistenk 1909; 15: $1-53$.

25.- Carter RF. Description of a Naegleria $s p$ isolated from two cases of primary amoebic meningo-encephalitis, and of the experimental changes induced by it. J Pathol 1970; 100: $217-44$. 
26.- Castellani A. An amoeba found in culture of a year: preliminay note. J Trop Med Hyg. June 2, 1930, p 160; second note: July 1, 1930, p 188; third note: August 1, 1930, p 221.

27.- Douglas M. Notes on the classification of the amoeba found by Castellani on culture of yeast-like fungus. J Trop Med Hyg 1930; 33: 258-59.

28.- Jahnes W G, Fulmer H M, Li CP. Free-living amoeba as contaminants in monkey kidney tissue cultures (23515). Proceed Soc Exp Biol Med 1957; 96: 484-8.

29.- Culbertson C G, Smith J W, Cohen H K, Minner J R. Experimental infection of mice and monkeys by Acanthamoeba. Am J Pathol 1959; 35: 185-97.

30.- Culbertson C G, Smith J W, Minner J R. Acanthamoeba: observation on animal pathogenicity. Sciencie 1958; 127; 1506.

31.- Ma P, Visvesvara GS, Martínez AJ, Theodore F H, Dagget P M, Sawyer T K, et al. Naegleria and Acanthamoeba infections: review. Rev Infect Dis 1990; 12: 490-513.

32.- Visvesvara G S, Martínez A J, Schuster F L, Leitch G, Wallace S V, Sawyer T K, Anderson M. Leptomyxid ameba, new agent of amebic meningoencaphalitis in human and animals. J Clin Microbiol 1990; 28: 2740-56.

33.- Gelman B B, Rauf S J, Nader R, Popov V, Borkowski J, Chaljub G, Nauta H W, Visvesvara GS. Amoebic encephalitis due to Sappinia diploidea. JAMA 2001; 16; 285 : 2450-1.

34.- Gelman B B, Popov V, Chaljub G, Nader R, Rauf S J, Nauta H W, Visvesvara G S. Neuropathological and ultrastructural features of amebic encephalitis caused by Sappinia diploidea. J Neuropathol Exp Neurol 2003; 62: 990-8.

35.- Corliss J O. An interim utilitarian ("userfriendly") hierarchical classification and characterization of the protists. Acta Protozool 1994; 33: 1-51.

36.- Cerva L, Kasprzak W, Mazur T. Naegleria fowleri in cooling waters of power plant. J Hyg Epidemiol Microbiol Inmunol 1982; 26: 152-61.

37.- Schuster F L. Cultivation of pathogenic and opportunistic free-living amebas. Clin Microbiol Rev 2002; 15, 342-54.

38.- Schuster F L, Dunnebacke T H, Booton G C, Yagi S, Kohlmeier C K, Glaser C, Vugia D,
Bakardjiev A, Azimi P, Maddux-González M, Martínez A J, Visvesvara G S.

Environmental Isolation of Balamuthia mandrillaris associated with a case of amebic encephalitis. J Clin Microbiol 2003; 41: 3175-80.

39.- Goodfellow L P, Belcher J H, Page F C. A light- and electron-microscopical study of Sappinia diploidea, a sexual amoeba. Protistologica 1974; 10: 207-16.

40.- Noble G A. Coprozoic protozoa from Wyoming mammals. J Protozool 1958; 5: 9-74.

41.- Mierowitz R L. Granulomatous Amebic Encephalitis and Disseminated Acanthamebiasis. En Mierowitz RL. (Ed). The Pathology of Opportunistic Infections. New York. Raven Press, 1982. pp 235-42.

42.- Wood GL, Gutierrez Y. Blood and Tissue Protozoa. Acanthamoeba and Leptomyxid amoeba.. En. GL Woods and Y. Gutierrez (Eds). Diagnostic Pathology of Infectious Diseases. Philadelphia. Lea \& Febirger. 1993 pp 502-3.

43.- Seidel J S, Harmatz P, Visvesvara G S, Cohen A, Edwards J, Turner J, et al. Successful treatment of primary amebic meningoencephalitis. N Engl J Med 1982; 306: 346-48.

44.- Kidelen A F, Laube U. Balamuthia mandrillaris, an opportunistic agent of granulomatous amebic encephalitis, infects the brain via the olfactory nerve pathway. Parasitol Res 2004; 94: 49-52.

45.- Schuster F L, Glaser C, Honarmand S, Maguire J H, Vivesvara G S. Emerg Infect Dis 2004; 10: 1510-2.

46. - Visvesvara G S, Schuster F L, Martínez J M. Balamuthia mandrillaris, n. g., n. sp., agent of amebic meningoencephalitis in humans and other animals. J Eukaryot Microbiol 1993; 40: 504-14.

47. - Booton G C, Jennifer R, Carmichael J R, Visvesvara G S, Byers T J, Paul A, Fuerst P A. Identification of Balamuthia mandrillaris by PCR assay using the mitochondrial 16S rRNA gene as a target. J Clin Microbiol 2003; 41: 453-5.

48. - Vodkin M H, Howe D K, Visvesvara G S, McLaughlin G L. Identification of Acanthamoeba at the generic and specific levels using the polymerase chain reaction. J Protozool 1992; 39: 378-85.
49.- Singhal T, Bajpai A, Kalra V, Kabra S K, Samantaray J C, Satpathy G, Gupta A K. Successful treatment of Acanthamoeba meningitis with combination oral antimicrobials. Pediatr Infect Dis J 2001; 20: 623-7.

50.- Slater C A, Sickel J Z, Visvesvara G S, Pabico R C, Gaspari A A. Brief report: successful treatment of disseminated Acanthamoeba infection in an immunocompromised patient. N Engl J Med 1994; 331: 85-7.

51.- Marciano-Cabral F, Cabral G. Acanthamoeba spp. as agents of disease in humans. Clin Microbiol Rev 2003; 16: 273307.

52.- Deetz T R, Sawyer M H, Billman G, Schuster F L, Visvesvera G S. Successful treatment of Balamuthia amoebic encephalitis: presentation of 2 cases. Clin Infect Dis 2003; 37: 1304-12.

53.- Stothard D R, Hay J, Schroeder-Diedrich J M, Seal D V, Byers T J. Fluorescent oligonucleotide probes for clinical and environmental detection of Acanthamoeba and the T4 18S rRNA gene sequence type. J Clin Microbiol 1999; 37: 2687-93.

54.- Ortega-Rivas A, Lorenzo-Morales J, Martinez E, Villa M, Clavel A, Valladares B, del Castillo A. A specific primer pair for the diagnosis and identification of Acanthamoeba astronyxis by random amplified polymorphic DNA-polymerase chain reaction. J Parasitol 2005; 91: 122-6.

55.- Khan N A, Greenman J, Topping K P, Hough V C, Temple G S, Pager T A. Isolation of Acanthamoeba-specific antibodies from a bacteriophage display library. J Clin Microbiol 2000; 38: 2374-7.

56. - Pfister D R, Cameron J D, Krachmer J H, Holland E J. 1996. Confocal microscopy findings of Acanthamoeba keratitis. Am J Ophthalmol 1996; 121:119-28.

57.- Torno M S, Babapour Jr R, Gurevitch A, UIT MD. Cutaneous acanthamoebiasis in AIDS. J Am Acad Dermatol 2000; 42: 351- 4.

58.- Bravo F G, Cabrera J, Gotuzzo E. Cutaneous manifestations of infections by free living amebas, with special emphasis on Balamuthia mandrillaris. En: SK Tyring, O Lupi, UR Henage (Eds). Tropical Dermatology. Ed. Churchill Livingstone. Philadelphia 2005; 49-56. 